\title{
Impact of Cutting Speed and Feed Rate for Cross Cutting with Saw Chains
}

\author{
Tomáš Kuvik,* Jozef Krilek, Ján Kováč, and Ján Melicherčík \\ This article examined the impact of cutting speed and feed rate on the \\ process of cross cutting with a saw chain. Three cutting speeds and three \\ feed rates were chosen, and their impact on energy intensity was \\ evaluated. The measurements were performed on an experimental \\ device, on which it is possible to set the rpm (cutting speed) and the feed \\ rate into the section using frequency converters. The cutting speed \\ influences the resulting energy efficiency, at a cutting speed (vc) of 5.02 \\ $\mathrm{m} \times \mathrm{s}^{-1}$ the resulting power $(\mathrm{P})$ was $485 \mathrm{~W}$. With increasing speed the \\ cutting power increased, where the maximum value of $P$ was $619 \mathrm{~W}$ at a \\ cutting speed of $6.81 \mathrm{~m}^{-1} \mathrm{~s}^{-1}$. At a feed rate of $0.286 \mathrm{~m} \times \mathrm{min}^{-1}$ the cutting \\ power was $376 \mathrm{~W}$, with increasing cutting speed the cutting power $(\mathrm{P})$ also \\ increased almost linearly up to the value of $695 \mathrm{~W}$ at a feed rate (vf) of \\ $0.857 \mathrm{~m} \times \mathrm{min}^{-1}$. The results showed that the cutting speed and the feed \\ rate have a clear influence on the process of cross sawing with a saw \\ chain.
}

Keywords: Saw chain; Feed rate; Cutting speed

Contact information: The Technical University in Zvolen, The Faculty of Technology, The Department of Environmental and Forestry Machinery, T. G. Masaryka 24, 96053 Zvolen, Slovakia;

*Corresponding author: t.kuvik14@gmail.com

\section{INTRODUCTION}

The cutting elements (teeth) in chainsaws are connected in one unit, and the saw chain moves freely along the guide bar. The guide bar orients the saw chain in the required direction, ensures that it remains stiff, and sets the cutting direction. The absence of a strong kinematic bond between the system of cutting elements and the body of the cutting member allows a more rational saw chain movement path, which reduces the contour dimensions of the cutting mechanism relative to the surface to be cut (Kováč et al. 2013)

The classification of cutting processes can be divided into continuous and discontinuous cutting (Kaczmarek 1971). Discontinuous cutting is characterized in that the cutters repeatedly enter and exit from material or skipping over its surface. In the scientific work dealing with this problem, it was assumed that if the pitch of the chain saw is lower than the kerf height, it is a continuous cutting, and each cutter produces continuous shavings (Douda 1974; Maciak 2001). The angular speed of the engine shaft, the weight of the chainsaw, and the number of teeth of the drive sprocket were found to significantly affect the changes in cutting resistance (Obliwin et al. 1988).

The individual links of the chain saw are connected via rivets subjected to tensile force. These links can deviate from the cutting plane during operation, which distinguishes the process of cutting with a chainsaw from other methods, such as cutting with circular saws or band saws (Maciak et al. 2018).

The saw chain is shown in Fig. 1. It has a simple construction, and the shape of its teeth makes it easier to work with when cutting. The saw chain is composed of only one 
type of teeth called cutter teeth, which are assembled alternately from the left and from the right. The teeth have two cutting edges, top and lateral, continuously connected at an angle of $90^{\circ}$ (Kováč et al. 2017).

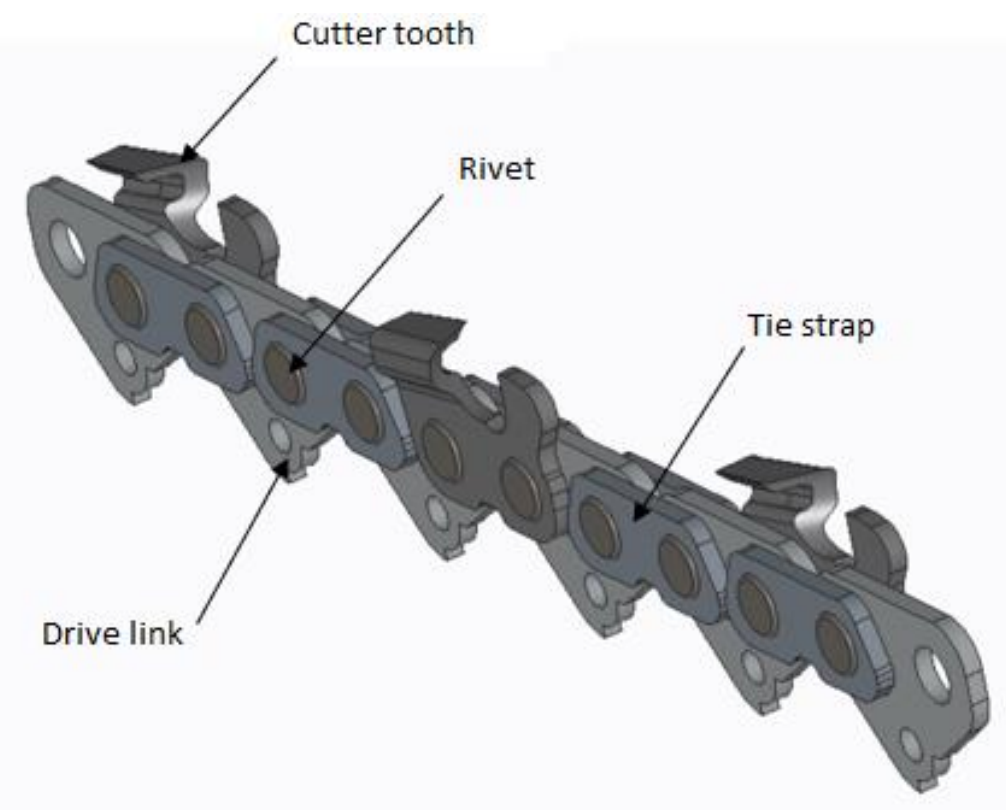

Fig. 1. Parts of the saw chain

The saw chain allows for effective cutting at any angle to the wood fibers. The saw chain does not choke and does not stop during cutting even if the feed force is increased. The height of cutting is the difference between the limiting foot and the cutting edge, which ranges from 0.8 to $1.4 \mathrm{~mm}$. The chain has a noticeably smaller number of teeth than that of the cutting chain. For example, the saw chain for a $500 \mathrm{~mm}$ guide bar has 22 teeth, and the cutting chain has 84 teeth. The running speed of saw chains ranges from 20 to $25 \mathrm{~m} \times$ $\mathrm{s}^{-1}$, which allows higher cutting performance (Štollmann and Slugeň 2009).

The guide bar fulfils the function of a chain guide. The body of the guide bar is made of one piece of material, which is typically steel, and it has a milled groove in it. The groove is adapted to guide the links of the chain. The body of the guide bar can also be made of three pieces, which are riveted or welded to each other, and the groove is formed by the space created between the three connected pieces. The chain guide generally has a clearance of approximately $0.05 \mathrm{~mm}$ in the grooves. The length of the saw chain ranges from approximately 30 to $90 \mathrm{~cm}$ (Kováč et al. 2013).

\section{Cutting Conditions for Chainsaws}

Chain speed and depth of cut are two important factors in chain cutting mechanics. Changes in chain speed and depth of cut can affect cutting forces and thus affect energy consumption and efficiency (Otto and Parmigiani 2015).

The basic parameters of chain saw mechanisms include the type of saw chain, saw chain size, cutting speed, and sliding speed. Because the cutting speed $\left(v_{\mathrm{c}}\right)$ is much higher than the feed rate $\left(v_{\mathrm{f}}\right)$, the optimum cutting speed and feed rate can be determined theoretically based on the kinematic relationships and the chip formation process under certain cutting conditions and for a certain saw chain (size and direction of the resulting cutting speed). 


\section{EXPERIMENTAL}

\section{Materials}

The experiment was based on laboratory measurements of cutting power, where selected parameters such as cutting speed and feed rate were changed. The measurements of the effects of the cutting speed and feed speed were taken on an experimental device with a Husqvarna chainsaw attachment. The chain used was a Husqvarna H 21 (Husqvarna Group, Stockholm, Sweden) with a 0.325 division and a Husqvarna guide bar with a length of $37 \mathrm{~cm}$ and a guide groove width of $1.5 \mathrm{~mm}$. The sample material was a $150 \mathrm{~mm} \times 150$ $\mathrm{mm} \times 1500 \mathrm{~mm}$ rectangular solid made of spruce wood, and it had a moisture content of $12 \%$. Three cutting speeds and three feed rates were used for measurement. The levels of the cutting speed and feed rate parameters for the experiment are in Table 1.

Table 1. Levels of Selected Parameters

\begin{tabular}{|c|c|c|c|}
\hline Levels & $\begin{array}{c}v_{\mathrm{c}} \\
\mathrm{m}^{-1} \mathrm{~s}^{-1}\end{array}$ & $\begin{array}{c}v_{f} \\
\mathrm{~m} \times \mathrm{min}^{-1}\end{array}$ & Wood \\
\hline 1. & 5.023 & 0.286 & \multirow{2}{*}{ Spruce (Picea abies) } \\
\hline 2. & 5.866 & 0.572 & \\
\hline 3. & 6.806 & 0.857 & \\
\hline
\end{tabular}

The experimental equipment (Fig. 2) consisted of three parts. The first part was a frame with a motor and a spindle on which a cutting mechanism made of a Husqvarna XP 550 chainsaw was mounted.

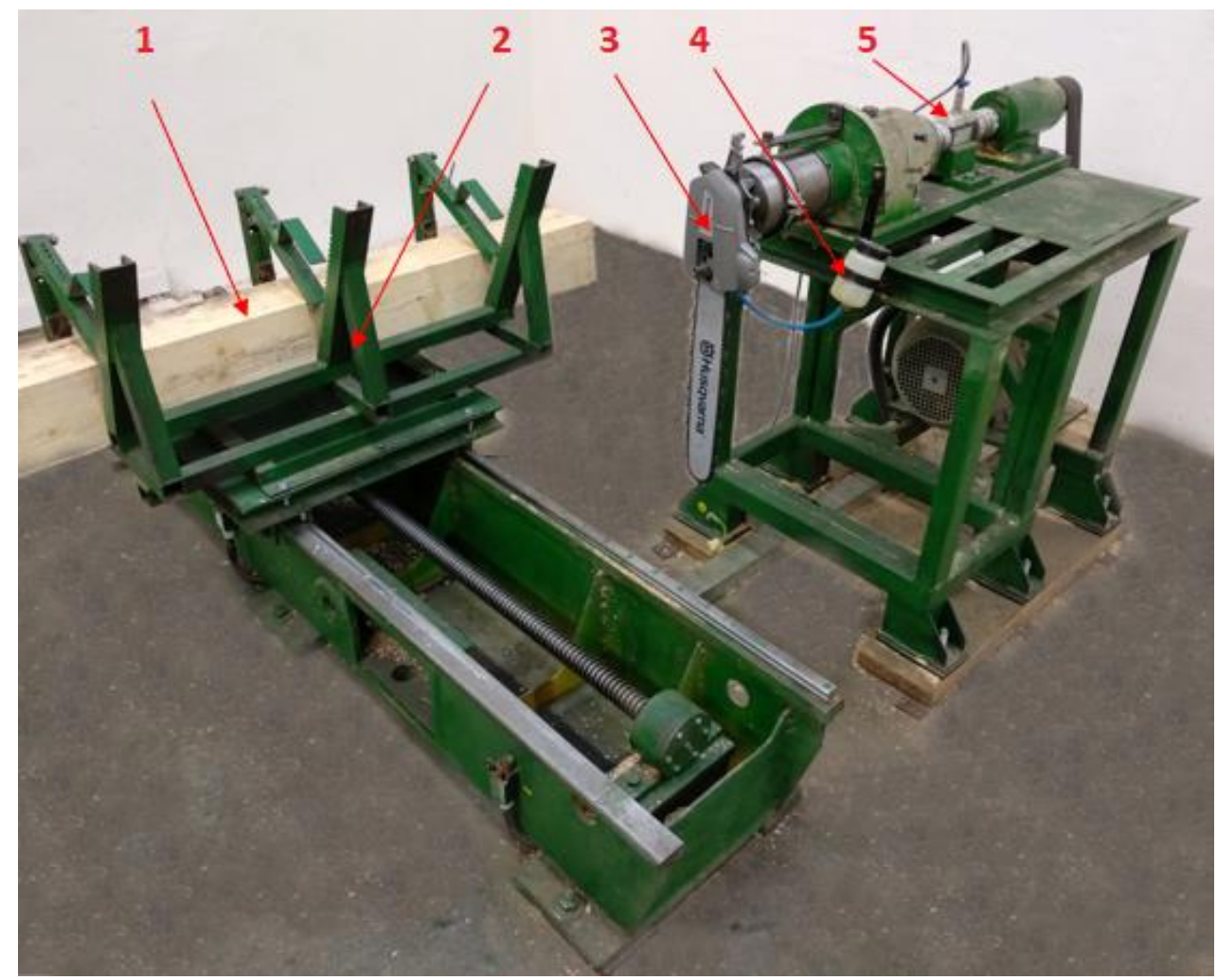

Fig. 2. The experimental device with a jig for holding the cutting mechanism of a chainsaw: (1) sample material; (2) trolley ensuring movement into the cut; (3) jig for holding the cutting mechanism of the chainsaw; (4) tank with oil; (5) HBM T20 WN torque and speed sensor 
The spindle was equipped with a strain gauge speed and torque sensor (HBM T20, Hottinger Brüel \& Kjaer GmbH, Darmstadt, Germany). The second part of the experimental equipment was a trolley with the sample material. The drive of the trolley was provided by a motor with a screw. The third part was a control unit comprised of control elements and frequency converters by means of which the cutting speed and the feed speed of the trolley were set.

\section{Torque and Speed Sensor}

The HBM T20WN torque and speed sensor (Fig. 3) were used to measure the torque and speed of the headstock. Its basic technical parameters are given in Table 2 . The sensor has its own power supply with a voltage of $12 \mathrm{~V}$. It has two output signals. It is a strain gauge torque sensor with built-in speed and angle measurement capabilities and contactless signal transmission. The characteristics indicate that the sensor is designed for a nominal torque of $20 \mathrm{Nm}$.

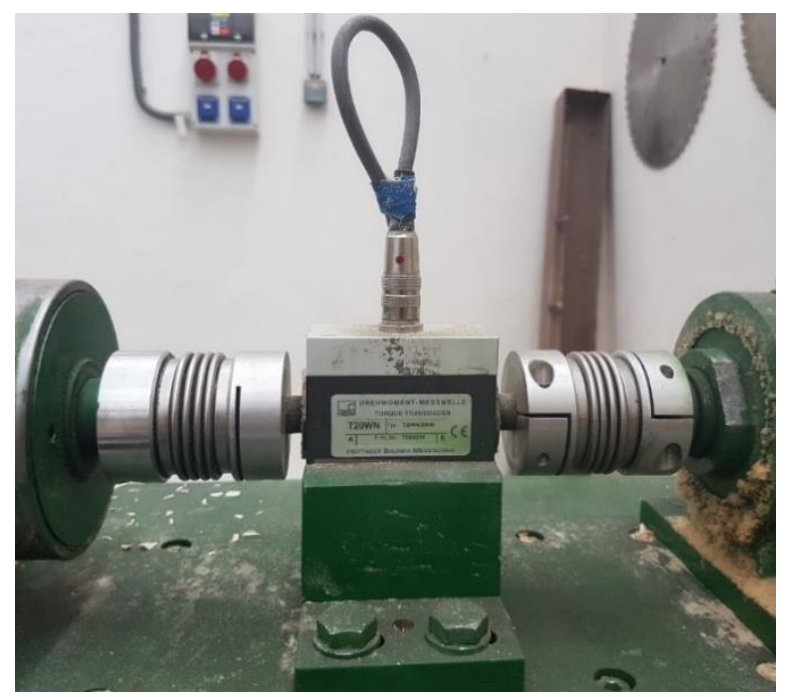

Fig. 3. Torque and speed sensor HBM T2OWN

The sensor is protected by two original flexible couplings that protect the sensor from deviations and throwing caused by misalignment of the shafts and limit the transmission of torque to $60 \mathrm{Nm}$.

Table 2. Basic Characteristics of the HBM T20WN Sensor

\begin{tabular}{|c|c|c|}
\hline Parameter & Unit & Value \\
\hline Nominal torque & $\mathrm{Nm}$ & 20 \\
\hline Maximum torque load & $\mathrm{Nm}$ & 60 \\
\hline Destructive torque load & $\mathrm{Nm}$ & 108 \\
\hline Nominal sensitivity & $\mathrm{V}$ & 10 \\
\hline Sensitivity tolerance & $\%$ & 0.2 \\
\hline Linearity error & $\%$ & $< \pm 0.1$ \\
\hline Relative error related to the change of the output signal & $\%$ & $<0.05$ \\
\hline
\end{tabular}


The measured data were processed and evaluated in the STATISTICS 12 program (STATISTICA12 software, TIBCO Software Inc., Palo Alto, CA, USA), using a twofactor analysis of power depending on the cutting speed and feed rate.

\section{RESULTS AND DISCUSSION}

Table 3 details the degree of significance of the factors, such as cutting speed, feed rate, and their interaction. The results indicated that the cutting speed and the feed rate influenced the size of the resulting power. However, their interaction was not statistically significant $(\mathrm{p}>0.05)$.

Table 3. Basic Table of Two-factor Analysis of Power Variance Depending on Cutting Speed and Feed Rate

\begin{tabular}{|c|c|c|c|c|c|}
\hline $\begin{array}{c}\text { Source of } \\
\text { Variability }\end{array}$ & $\begin{array}{c}\text { Sum of } \\
\text { Squares }\end{array}$ & $\begin{array}{c}\text { Degrees of } \\
\text { Freedom }\end{array}$ & Variance & F-test & $\begin{array}{c}\text { p-level of } \\
\text { Significance }\end{array}$ \\
\hline Absolute value & $\mathbf{1 5 7 5 8 7 7 5}$ & $\mathbf{1}$ & $\mathbf{1 5 7 5 8 7 7 5}$ & $\mathbf{4 3 9 0 . 5 2 3}$ & $\mathbf{0 . 0 0 0 0 0 0}$ \\
\hline$v_{c}$ & $\mathbf{1 6 2 5 0 8}$ & $\mathbf{2}$ & $\mathbf{8 1 2 5 4}$ & $\mathbf{2 2 . 6 3 8}$ & $\mathbf{0 . 0 0 0 0 0 0}$ \\
\hline$v_{f}$ & $\mathbf{9 2 4 6 9 6}$ & $\mathbf{2}$ & $\mathbf{4 6 2 3 4 8}$ & $\mathbf{1 2 8 . 8 1 4}$ & $\mathbf{0 . 0 0 0 0 0 0}$ \\
\hline$v_{c}{ }^{*} v_{f}$ & 11691 & 4 & 2923 & 0.814 & 0.522776 \\
\hline Error & 161517 & 45 & 3589 & & \\
\hline
\end{tabular}

Figure 4 shows $95 \%$ confidence intervals for the mean power values depending on the cutting speed. The graph shows that as the cutting speed increased, the value of the cutting power increased.

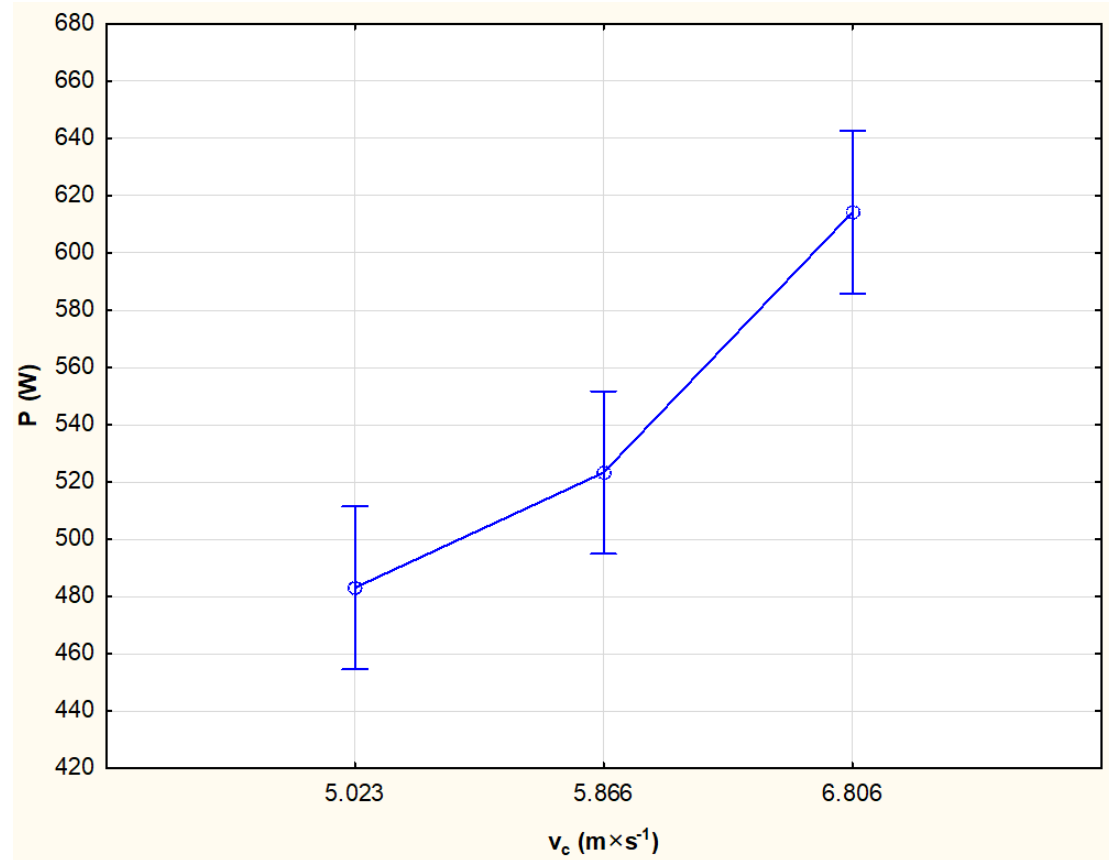

Fig. 4. 95\% confidence intervals for the mean power values depending on cutting speed 
Figure 5 shows $95 \%$ confidence intervals for cutting power as a function of feed rate. The lowest value of the cutting power was at a feed rate of $0.286 \mathrm{~m} \times \mathrm{min}^{-1}$ and reached the value of $376 \mathrm{~W}$. Gradually, with increasing feed rate, the cutting power also increased almost linearly. The highest value of cutting power $695 \mathrm{~W}$ was at a cutting speed of $0.857 \mathrm{~m} \times \mathrm{min}^{-1}$.

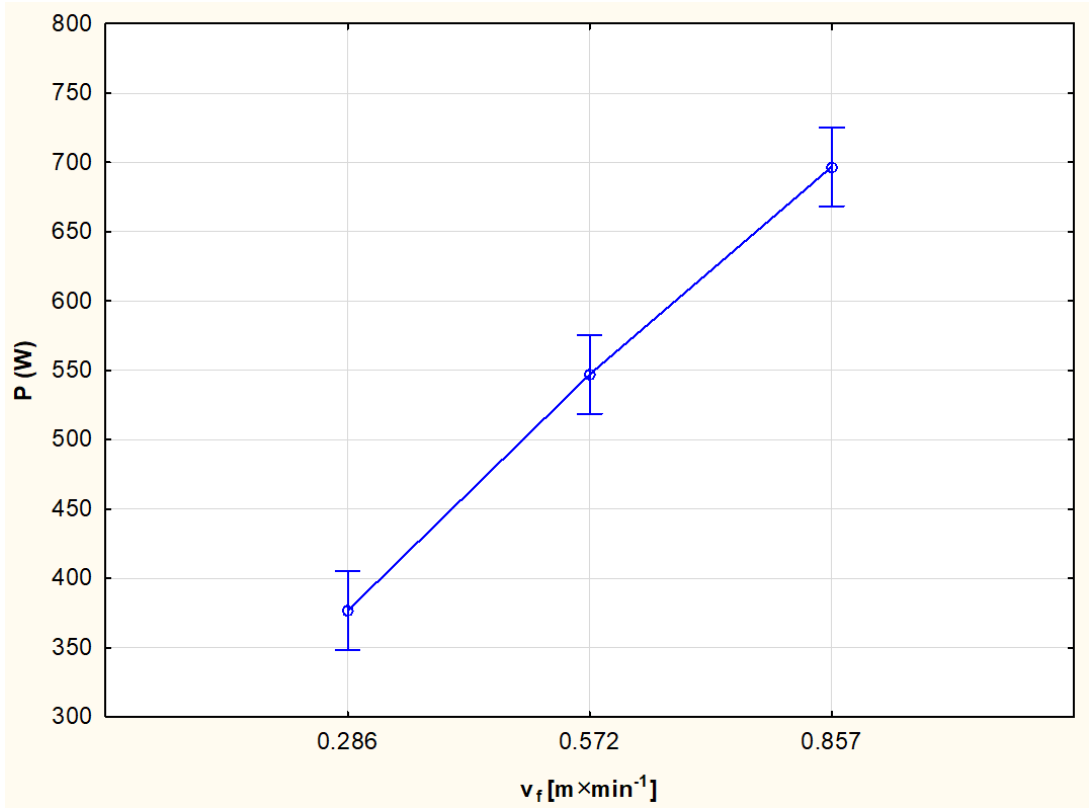

Fig. 5. 95\% confidence intervals for the mean power values depending on the feed speed

Table 4 shows that the lowest energy intensity was at the cutting speed of $5.023 \mathrm{~m}$ $\times \mathrm{s}^{-1}$ and the feed rate of $0.286 \mathrm{~m} \times \mathrm{min}^{-1}$. In contrast, the energy intensity was the highest at the cutting speed of $6.81 \mathrm{~m} \mathrm{x} \mathrm{s}^{-1}$ and the feed speed $v_{\mathrm{f}}=0.857 \mathrm{~m} \times \mathrm{min}^{-1}$.

Table 4. Basic Statistical Table of Performance

\begin{tabular}{|c|c|c|c|c|c|c|c|}
\hline & $\boldsymbol{V}_{\mathbf{c}}$ & $\mathbf{V}_{\mathbf{f}}$ & $\begin{array}{c}\mathbf{P} \\
\mathbf{M e a n}\end{array}$ & $\begin{array}{c}\mathbf{P} \\
\text { Std. Dev }\end{array}$ & $\begin{array}{c}\mathbf{P} \\
-95.00 \%\end{array}$ & $\begin{array}{c}\mathbf{P} \\
+95.00 \%\end{array}$ & $\mathbf{N}$ \\
\hline 1 & 5.023 & 0.286 & 296.857 & 24.45837 & 247.5953 & 346.1187 & 6 \\
\hline 2 & 5.023 & 0.572 & 504.2418 & 24.45837 & 454.9801 & 553.5035 & 6 \\
\hline 3 & 5.023 & 0.875 & 648.1812 & 24.45837 & 598.9195 & 697.4429 & 6 \\
\hline 4 & 5.866 & 0.286 & 356.1311 & 24.45837 & 306.8694 & 405.3928 & 6 \\
\hline 5 & 5.866 & 0.572 & 535.5149 & 24.45837 & 486.2532 & 584.7766 & 6 \\
\hline 6 & 5.866 & 0.875 & 678.27 & 24.45837 & 629.0083 & 727.5317 & 6 \\
\hline 7 & 6.806 & 0.286 & 476.8793 & 24.45837 & 427.6176 & 526.141 & 6 \\
\hline 8 & 6.806 & 0.572 & 601.4681 & 24.45837 & 552.2064 & 650.7298 & 6 \\
\hline 9 & 6.806 & 0.875 & 764.366 & 24.45837 & 715.1043 & 813.6277 & 6 \\
\hline
\end{tabular}




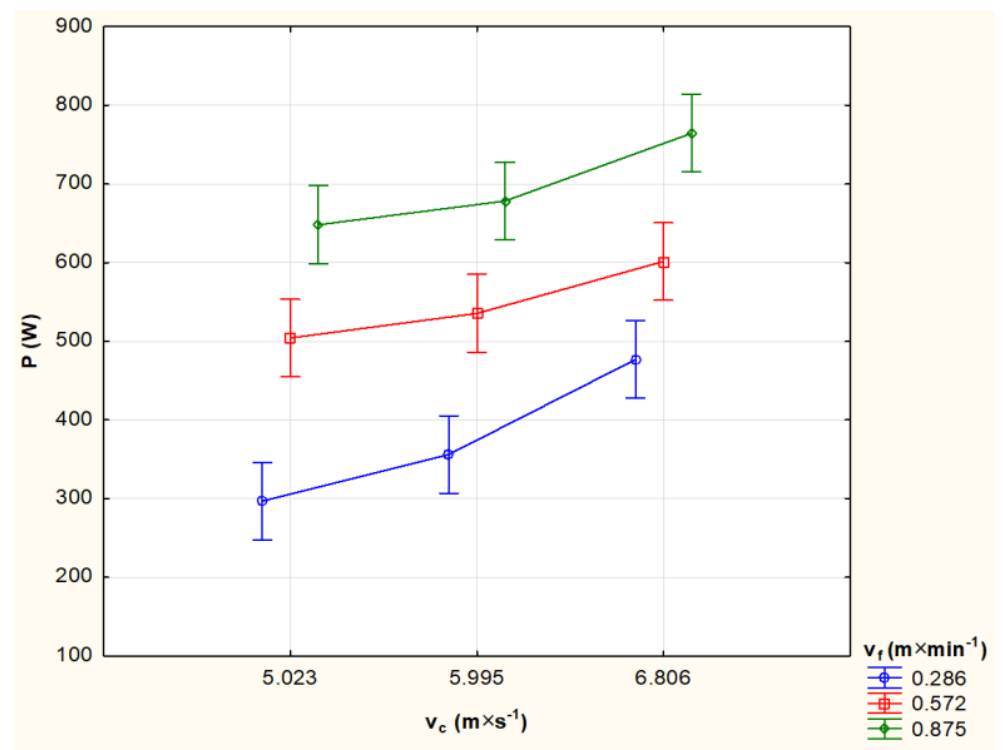

Fig. 6. 95\% confidence intervals for the mean power values depending on feed and cutting speed

Various methods and devices have been proposed to research the cross-sawing process. Maciak (2015) used a complete chainsaw that was fixed to the table, and the workpiece was moved to the cut. Otto and Parmigiani (2015) used a test apparatus in which a guide bar with a saw chain and a sprocket was used. In this study, the entire cutting mechanism (engine block, oil pump, clutch drum, sprocket, guide bar, chain, and tensioning device) was used, and it was mounted on the experimental device. The solution used in this study was better than the mounting of a complete chainsaw (Maciak et al. 2018), as it allowed precise setting of the cutting speed. The test apparatus in which only the guide bar with the sprocket is mounted (Otto and Parmigiani 2015) is similar to the apparatus used in this study, but it was possible to describe its overall impact on the sawing process because the entire cutting mechanism was used.

When sawing with a saw chain, the guide bar slides smoothly into the cut. If the chain speed or feed rate is disproportionate, the chain may jam or, in extreme cases, rupture or damage the cutting mechanism. Therefore, a suitable chain speed must be met, which maintains the cutting speed and ensures a smooth movement into the cut.

The saw chain mechanism was measured to determine the energy intensity at the specified cutting and feed rates. Measurements were performed when sawing spruce wood, which composes the largest proportion of wood in Slovakia. Performance as an indicator of energy intensity was determined depending on the feed and cutting speed. As the cutting speed and feed rate increased, the value of the energy dependence increased.

\section{CONCLUSIONS}

1. As the cutting speed increased, the magnitude of the resulting power increased approximately linearly. At the cutting speed $\left(v_{c}\right)$ of 5.023, the power variance $(P)$ was approximately $48 \underline{5} \mathrm{~W}$. The highest power was observed at the highest $v_{\mathrm{c}}$ of 6.81 , and the average variance was $619 \mathrm{~W}$. 
2. The dependence of the power on the sliding speed was approximately linear, and the power value increased as the sliding speed increased. At a feed rate $(v f)$ of 0.286 , the cutting power was the lowest and reached a value of $376 \mathrm{~W}$. At a cutting speed $\left(v_{\mathrm{f}}\right)$ of 0.857, the cutting power was the highest and reached the value of $695 \mathrm{~W}$.

3. The influences of the individual factors on the final output were statistically significant, but the mutual interaction of cutting speed and feed rate was not statistically significant.

\section{ACKNOWLEDGMENTS}

This experimental research was financially supported by Grant No. VEGA 1/0609/20: "Research of the cutting tools at the dendromass processing in agricultural and forestry production."

\section{REFERENCES CITED}

Douda, V. (1974). Mechanizačníprostředkylesnické a Jejichpoužití; Státní Zemědělské Nakladatelství [Forestry Mechanization Means and Their Use], State Agricultural Publishing House (SZN), Prague, Czechoslovakia.

Kaczmarek, J. (1971). The Basics of Turning, Abrasive, and Erosive Machining, WNT, Warsaw, Poland. (In Polish)

Kováč, J., Krilek, J., Kučera, M., Kopecký, Z., and Hlásková, L. (2013). Ergonomic Process Parameters Cutting Wood, Mendel University in Brno, Brno, Czech Republic.

Kováč, J., Krilek, J., Jobbágy, J., and Dvořák, J. (2017). Technika a Mechanizacia v Lestníctve [Technique and Mechanization in Forestry], Technical University in Zvolen, Zvolen, Slovakia.

Maciak, A. (2001). Influence of Construction Parameters of Chain Saw Cutters on Wood Cutting Efficiency, Ph.D. Thesis, Warsaw University of Life Sciences, Warsaw, Poland. (In Polish)

Maciak, A. (2015). "Impact of the feed force on discontinuity of wood cutting with petrol chainsaw," Annals of Warsaw University of Life Sciences - SGGW, Agriculture (Agricultural and Forest Engineering) 66, 99-1010.

Maciak, A., Kubuśka, M., and Moskalik, T. (2018). "Instantaneous cutting force variability in chainsaws," Forests 9(10), Article Number 660. DOI: 10.3390/f9100660

Obliwin, W. N., Sokolow, A. M., and Liejtas, M. (1988). Ergonomics in the Forest Supply Industry, Izdatielstwo Liesnaja Promyszliennost, Moscow, Russia. (In Russian)

Otto, O., and Parmigiani, J. (2015). "Velocity, depth-of-cut, and physical property effects on saw chain cutting," BioResources 10(4), 7273-7291. DOI:

10.15376/biores.10.4.7273-7291 
Siklienka, M., Kminiak, R., Šustek, J., and Jankech, A. (2017). Delenie a Obrábanie Dreva [Splitting and Woodworking], Technical University in Zvolen, Zvolen, Slovakia.

Štollmann, V., and Slugeň, J. (2009). Lesnícke Mechanizačné Prostriedky [Forestry Means of Mechanization], Technical University in Zvolen, Zvolen, Slovakia.

Article submitted: April 5, 2021; Peer review completed: May 23, 2021; Revised version received and accepted: June 1, 2021; Published: June 8, 2021.

DOI: $10.15376 /$ biores.16.3.5341-5349 